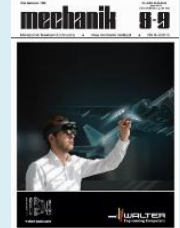

\title{
Methods of minimum uncut chip thickness estimation during cutting with defined geometry tools
}

\author{
Metody szacowania minimalnej grubości warstwy skrawanej \\ podczas obróbki narzędziami o zdefiniowanej geometrii
}

\section{SZYMON WOJCIECHOWSKI*}

\begin{abstract}
Methods of minimum uncut chip thickness estimation during cutting with defined geometry tools were presented. Approaches were divided into experimental, analytical, and numerical. It has been presented that applied methods concern mainly orthogonal turning, however only a few consider tools with rounded cutting edges.
\end{abstract}

KEYWORDS: cutting, minimum uncut chip thickness, tools with defined geometry

Due to the occurrence of elastic deformations of the workpiece and a non-zero radius of the main cutting edge $r_{n}$, a certain volume of material flowing into the cutting edge is not converted into a chip, but pressed under the flank face $A_{\alpha}$ of the tool. It should be emphasized that this phenomenon acquires a significant meaning especially in the case of precision machining, where the cutting layer is thin.

\section{Concept of the minimum thickness of a machined layer}

Fig. 1 shows a schematic of the material layer moving relative to the rounded tool cutting edge during orthogonal free cutting. If the thickness of the cutting layer is in the range: $0<h<h_{\mathrm{s}}$, the material undergoes only elastic deformations of the value $\Delta_{s}$ and after passing the cutting edge returns to the nominal position. Increasing the thickness of the machined layer to a value within the range: $h_{\mathrm{s}} \leq h<h_{\min }$ causes elastic-plastic and plastic deformations of the material. The effect of this is the formation of a plastic flash (at the interface of the tool flank face with the workpiece), which is not converted into chips. Further increase of the thickness of the cutting layer to the value included in the range: $h \geq h_{\min }$ only leads to the initiation of cutting and thus the phenomenon of chip formation.

From these considerations, it results that one of the most important factors characterizing the decohesion of the material is the minimum thickness of the machined layer $h_{\min }$. This value determines the critical value of the thickness of the cutting layer, initiating shear and converting the material to chip.

* Dr inż. Szymon Wojciechowski (szymon.wojciechowski@ put.poznan.pl) - Zakład Obróbki Skrawaniem Politechniki Poznańskiej
As can be seen from the tests [1], the minimum thickness of the cutting layer depends on the radius of the cutting edge rounding, the machining parameters as well as the properties of the workpiece and tool material. This relationship can be described by the general equation:

$$
h_{\min }=k \cdot r_{n}
$$

The coefficient $k$ is called the normalized minimum thickness of the cutting layer (normalized minimum uncut chip thickness). Its value depends on the mechanical properties of the workpiece and tool material, cutting parameters (mainly speed $-v_{c}$ ), as well as tribological phenomena at the interface between the material and the tool. Therefore, the problem of estimating $h_{\min }$ is mainly based on a meaningful determination of the value of parameter $k$.

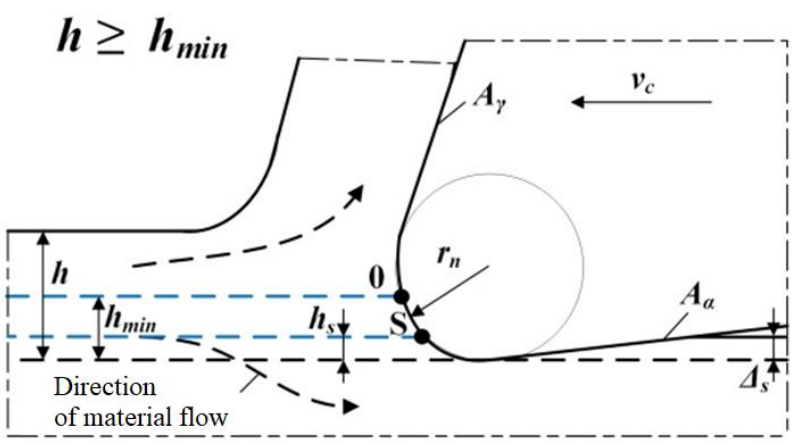

Fig. 1. Diagram of the movement of an elastic plastic workpiece against the cutting edge during free orthogonal cutting; $h$ thickness of the machined layer, $h_{\min }$ - minimum thickness of the machined layer, $h_{\mathrm{s}}$ - limiting thickness of the machined layer corresponding to elastic deformations, $\Delta_{s}$ - elastic return of material

Analytical methods for determining the minimum thickness of the machined layer

Analytical methods take into account the physical phenomena occurring during chip forming and are based on constitutive models of the material being cut or identification of the material stagnation point.

The model developed in [2] for micro-milling of 1040 steel and Al6082-T6 alloy, takes into account the criterion of the transition between plastic deformation and micro- 
scratching in the scratch test and refers them to micromilling. Based on this model, the normalized minimum thickness of the machined layer is expressed as:

$$
k=\frac{h_{\min }}{r_{n}}=0,5-\frac{\tau_{a}}{\sigma}
$$

where: $T_{\alpha}$ - shear strength of adhesive joints, $\sigma$ - shear stress strengthened by the work of chips.

To determine the coefficient $k$ described by (2), the parameters $\tau_{\alpha}$ and $\sigma$ should be determined.

During cutting, the slip stress value $\sigma$ depends on the temperature, as well as the size and speed of deformation of the workpiece. Therefore, in order to determine meaningfully the stress value $\sigma$, in the range of high temperatures and distortions, so-called constitutive models are applied. According to studies [3], Johnson-Cook's constitutive model can be successfully used to determine the value of slip stresses for aluminum and titanium alloys. Its accuracy is limited in relation to stress modeling $\sigma$ for carbon steels. In the case of these materials, the alternative may be the Oxley constitutive model.

The Johnson-Cook's model expresses the slip stress as a function of temperature, strain and strain rate of the workpiece, as follows:

$$
\sigma=\left[A+B(\varepsilon)^{n_{\tau}}\right] \cdot\left[1+m_{\tau} \cdot \ln \left(v_{\varepsilon}\right)\right] \cdot\left[1-\left(\frac{T_{A}-T_{R}}{T_{T}-T_{R}}\right)^{v_{\tau}}\right]
$$

where: $A, B$ - experimentally determined values, $\varepsilon$ - substitute plastic deformation, $n_{\mathrm{T}}-$ strengthening coefficient, $m_{\mathrm{T}}-$ constant describing sensitivity of deformation velocity, $v_{\varepsilon}-$ plastic deformation rate, $T_{\mathrm{A}}$ - absolute temperature, $T_{\mathrm{R}}$ - reference temperature, $T_{T}-$ melting temperature, $v_{T}-$ thermal strain factor.

The use of the Oxley model allows to determine the value of the slip stress in the form of the exponential function:

$$
\sigma=\sigma_{1} \varepsilon^{n_{1}}
$$

where: $\sigma_{1}-$ strength coefficient, $n_{1}$ - exponent, taking into account the hardening of material.

The analytical model developed by Ernst and Merchant can be used to determine the shear strength of $\tau_{\alpha}$ adhesive joints during machining. This approach is based on the Clausius-Clapeyron equation:

$$
\tau_{a}=0,142 Q_{m} \cdot \rho \cdot \ln \left(\frac{T_{T}}{T_{w-n}}\right)
$$

where: $Q_{m}$ - heat of material melting, $\rho$ - material density, $T_{\mathrm{w}-\mathrm{n}}-$ temperature at the chip-tool contact surface

Determining the coefficients in equations (3-5) is possible by applying the slip-line field theory, developed in [4]. This approach refers to micro-machining processes as it takes into account the heat sources originating from: mechanical shear energy along the slip plane, chip friction surface area, as well as friction phenomena in the area of the rounded cutting edge radius.

Another group of analytical models are approaches based on determining the so-called a stagnation point of 0 , located on the rounded cutting edge. At this point there is a change in the direction of flow of the workpiece in relation to the cutting edge. Therefore, the position of point 0 determines the value of the minimum thickness of the machined layer. It should be emphasized that the point of stagnation is the boundary between the real flank and rake faces.

The authors [5] formulated an analytical $h_{\min }$ model referring to turning. It was based on the analysis of tangential forces $F_{\text {trn }}$ affecting the rounded cutting edge. The formulated force models were expressed as a linear function of the thickness of the machined layer. The authors assumed that the increase in tangent forces at the point of stagnation is zero $\left(\Delta F_{\mathrm{trn}}=0-\mathrm{fig}\right.$. 2). This made it possible to determine the angle of stagnation $\beta_{\mathrm{kr}}$ in accordance with the dependence:

$$
\beta_{k r}=\operatorname{arcctg}\left(\frac{a_{f}}{a_{c}}\right)
$$

where: $a_{\mathrm{f}}, a_{\mathrm{c}}$ - directional coefficients in linear regression equations of feed force and cutting force.

Determination of the expression describing the angle of stagnation $\beta_{\mathrm{kr}}$ allows, after the formulation of the minimum equation, the thickness of the machined layer:

$$
h_{\min }=r_{n}\left(1-\cos \beta_{k r}\right)=r_{n}\left[1-\cos \left(\operatorname{arcctg}\left(\frac{a_{f}}{a_{c}}\right)\right)\right]
$$

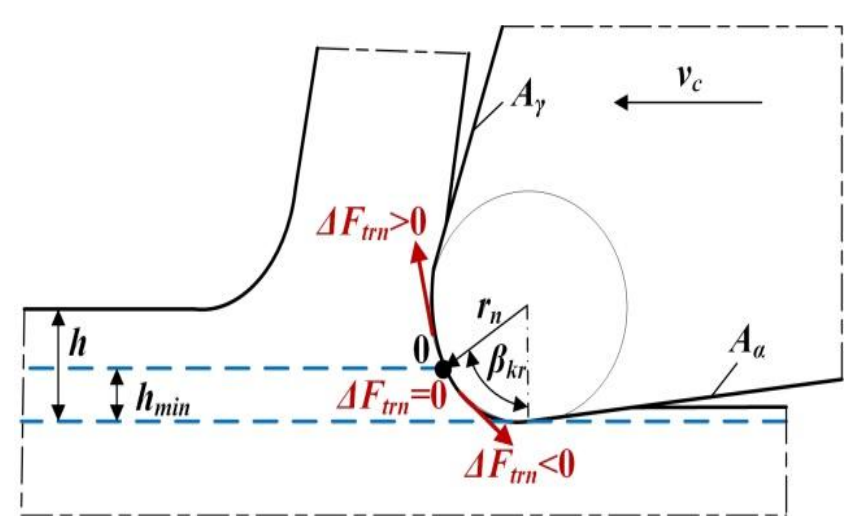

Fig. 2. Distribution of variation of tangential forces along the rounded cutting edge during orthogonal cutting

\section{Simulation methods for determining the minimum thickness of the machined layer}

The next group of methods for determining the minimum thickness of the machined layer is based on the simulation of the cutting process based on numerical calculations. These approaches mainly use the Finite Element Method (FEM) or Molecular Dynamics (MD).

The literature review shows that FEM modeling in relation to the prediction of the minimum layer thickness during metal processing is based on the use of Johnson-Cook and Bammann-Chiesa-Johnson (BCJ) constitutive models [6]. The authors [7] used the FEM model based on the JohnsonCook equation with respect to the simulation of the chip forming process and $h_{\min }$ during the orthogonal micro-cutting of copper with a polycrystalline diamond tool.

With regard to precision machining, carried out with small thicknesses of the machined layer, the traditional JohnsonCook model can be characterized by reduced accuracy. The reason for this is so-called size effect, caused by the occurrence of negative values of effective rake angles during machining with the thickness of the machined layer in the $h \approx r_{\mathrm{n}}$ range. This results in an intense increase in compressive stresses in the area of the rounded cutting edge, which can lead to a significant strengthening of the workpiece. 


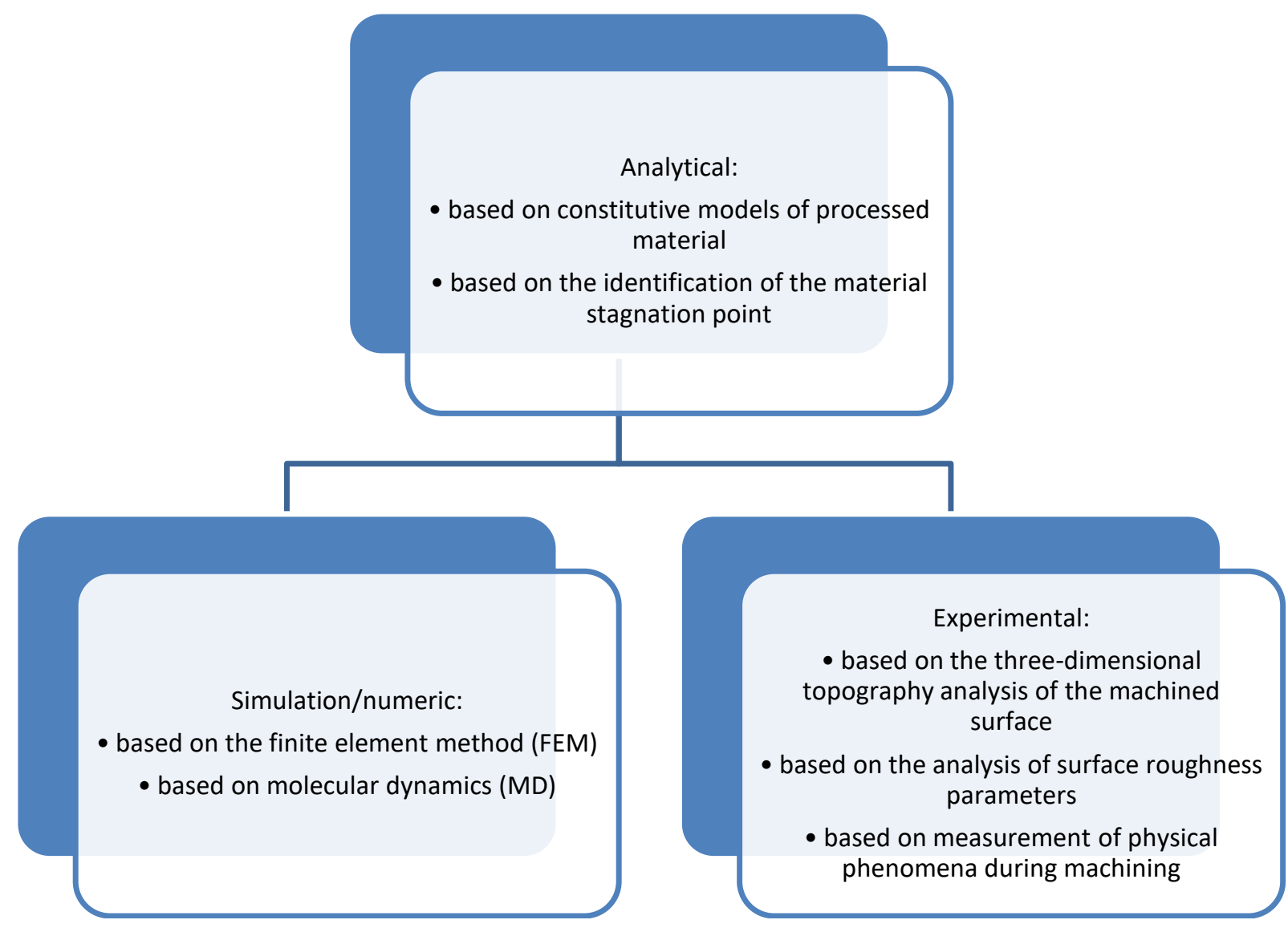

Fig. 3. Division of methods for determining the minimum thickness of the machined layer

Therefore, the authors [8] proposed a modified JohnsonCook model including the theory of plasticity of the FleckHutchinson deformation gradient, in order to estimate the minimum thickness of the cutting layer during micro-finding of peripheral copper. The constitutive model they developed took into account the temperature, size and speed of deformation of the workpiece as well as the length of the main slip zone.

The simulation of the chip forming process along with the estimation of the minimum thickness of the cutting layer can also be made based on the molecular dynamics (MD) method. It uses the principles of Newtonian dynamics in relation to atoms, whereby the Newton equation is then solved by numerical integration of the trajectory of each atom [9].

In molecular dynamics, forces acting on atoms are calculated on the basis of the potential function, which describe the energetic relations between atoms, taking into account distance and angle of binding. In this way, MD simulations take into account the characteristics of the material in detail and enable accurate estimation of dislocation, specific energy of cutting and propagation of cracks.

\section{Experimental methods for determining the minimum thickness of the machined layer}

The last group of methods for determining the minimum thickness of the machined layer is based on experimental investigations. Experimental methods enable estimation of $h_{\min }$ both directly, e.g. by evaluating the topography and roughness of the machined surface, and indirectly, by measuring and analyzing physical phenomena correlated with the phenomenon of the minimum thickness of the machined layer (e.g. measurement of the components of total force, acoustic emission).

The authors [10] evaluated the surface of the brittle SiC, obtained by planning a conical groove, in order to directly determine the minimum uncut chip thickness and boundary layer of the thickness of the plastic fracture. The tests were carried out on an ultra-precision lathe with the cutting speed $v_{\mathrm{c}}=1.5 \mathrm{~mm} / \mathrm{s}$ and the angle of inclination of the sample to a level of $0.03^{\circ}$. Additionally, in order to minimize the impact of the nominal surface roughness of the material on the obtained results, the sample was polished.

The authors [11] developed a method for determining $h_{\text {min }}$ based on the measurement of components of total force and surface roughness in relation to micro-milling of 1045 steel. In order to identify the extent of occurrence of the minimum thickness of the machined layer, they adopted the ratio of specific cutting pressure to surface roughness $k_{\mathrm{d}} / R_{\mathrm{a}}$. According to their assumptions, this coefficient informs about the intensity of the ploughing phenomenon and the formation of microcracks in the material. Therefore, the area in which a rapid increase in $k_{\mathrm{c}} / R_{\mathrm{a}}$ is observed is associated with a reduction in the thickness of the cutting layer below the value of $h_{\min }$.

The test results presented in [11] showed that for steel 1045 , the range of $h_{\min }$ occurrence corresponds to $k_{\mathrm{c}} / R_{\mathrm{a}}$ values in the range of $200 \div 280 \mathrm{GPa} / \mu \mathrm{m}$. This was also confirmed by SEM analysis of machined surfaces.

\section{Conclusions}

In view of the intensively developing precision machining technology, the importance of the problem of the minimum thickness of the machined layer contributed to the development of many measurement and computational methods at the turn of several decades. In a conventional way, these methods can be divided into analytical, simulative and experimental (fig. 3).

Regardless of the approach, the methods used by researchers to estimate the minimum thickness of a machined layer usually apply to orthogonal free cutting (mainly turning). However, there are few models for cutting tools with a rounded corners of the cutting edges. 
Meanwhile, in practice, these types of cutting edges are used very often.

According to many studies, the shape of the cutting edge significantly affects the distribution of forces affecting the tool, and also - for some tools - also for changing the cutting speed along the cutting edge. The variability of these quantities can have a significant effect on the decohesion process of the material, and in this way - on the value of the minimum thickness of the machined layer. It is therefore advisable to carry out further research on the estimation of the minimum thickness of the cutting layer for different cutting methods and tools with different contours of the cutting edge.

\section{REFERENCES}

1. Kawalec M. „Fizyczne i technologiczne zagadnienia przy obróbce z małymi grubościami warstwy skrawanej". Rozprawa nr 106. Wydawnictwo Politechniki Poznańskiej (1980).

2. Liu X., DeVor R.E., Kapoor S.G. "An analytical model for the prediction of minimum chip thickness in micromachining". Transactions of the ASME. 128 (2006): pp. 474-481.

3. Jaspers S.P.F.C., Dautzenberg J.H. "Material behavior in conditions similar to metal cutting: Flow stress in the primary shear zone". J. Mater. Process. Technol. 122 (2002): pp. 322-330.

4. Liu X., Jun M.B.G., DeVor R.E., Kapoor S.G. "Cutting Mechanisms and Their Influence on Dynamic Forces, Vibrations and Stability in Micro-Endmilling". Anaheim, Stany Zjednoczone: American Society of Mechanical Engineers (2004).

5. Storch B., Zawada-Tomkiewicz A. "Distribution of unit forces on the tool edge rounding in the case of finishing turning". Int J Adv Manuf Technol. 60 (2012): pp. 453-461.

6. Bammann D.J., Johnson G.C. "On the kinematics of finite-deformation plasticity". Acta Mech. 70 (1987): pp. 113.

7. Moriwaki T., Sugimura N., Luan S. "Combined stress material flow and heat analysis of orthogonal micromachining of copper". Annals of CIRP. 42 (1993): pp. 75-78.

8. Lai X.M., Li H.T., Li C.F., Lin Z.Q., Ni J. "Modeling and analysis of micro scale milling considering size effect, micro cutter edge radius and minimum chip thickness". International Journal of Machine Tools \& Manufacture. 48 (2008): pp. 1-14.

9. Oluwajobi A. "Molecular Dynamics Simulation of Nanoscale Machining, Molecular Dynamics - Studies of Synthetic and Biological Macromolecules". Prof. Lichang Wang (Ed.), ISBN: 978-953-51-0444-5. InTech (2012).

10. Xiao G, To S., Zhang G. "Molecular dynamics modeling of brittle-ductile cutting mode transition: Case study on silicon carbide". International Journal of Machine Tools \& Manufacture. 88 (2015): pp. 214-222.

11. De Oliveira F.B., Rodrigues A.S., Coelho R.T., de Souza A.F. "Size effect and minimum chip thickness in micromilling". International Journal of Machine Tools \& Manufacture. 89 (2015): pp. 39-54.

Translation of scientific articles, their computer composition and publishing them on the website www.mechanik.media.pl by original articles in Polish is a task financed from the funds of the Ministry of Science and Higher Education designated for dissemination of science. 